\title{
Solutions for Retention of Female Cardiologists From the Survey of Gender Differences in the Work and Life of Cardiologists
}

\author{
Yayoi Tetsuou Tsukada, MD; Miwa Tokita, MD; Kazuyo Kato, MD; Yuko Kato, MD; \\ Mizuho Miyauchi, MD; Isuzu Ono, MD; Hiroko Tanabe, MD; Tomoko Yokoshima, MD; \\ Hiroko Fukumoto, MD; Yoshiko Miyatake, MD; Kyoichi Mizuno, MD
}

\begin{abstract}
Background: To prevent a future shortage of cardiologists, it is important for female cardiologists to continue working. Gender differences in the professional and private lives of cardiologists, as well as the barriers to work for female cardiologists, were surveyed.

Methods and Results: In August 2007, a questionnaire was mailed to all 195 faculty members/fellows and 155 alumni of the Department of Cardiovascular Medicine at Nippon Medical School. More female cardiologists were dissatisfied with their job than male cardiologists ( $34 \%$ vs $17 \%, \mathrm{P}<0.005)$. Women reported greater career limitation by family responsibilities and housework. Men and women both reported that long working hours was the most problematic issue, but significantly more women reported this than men $(76 \%$ vs $94 \%, \mathrm{P}<0.05)$. Female cardiologists were more concerned about occupational radiation exposure $(88 \%$ vs $59 \%, \mathrm{P}<0.01)$ and wanted opportunities for retraining after childcare leave $(100 \%$ vs $76 \%, \mathrm{P}<0.01)$.

Conclusions: The following measures should be taken: (1) establishment of more family-friendly working conditions in hospitals, (2) provision of various work positions that allow more flexibility and predictability for women, (3) establishment of a retraining system, and (4) development of work and research opportunities that are attractive to women. The Japanese Circulation Society is expected to establish a retraining system at certified institutions. (Circ J 2009; 73: 2076-2083)
\end{abstract}

Key Words: Carrier; Education; Gender issue; Job satisfaction; Women

$\mathbf{O}$ ver the past 3 decades, the number of female medical school students has increased markedly in Japan. According to the School Basic Survey performed by the Ministry of Education, Culture, Sports, Science and Technology, the number of women entering medical school was only $493(10.5 \%)$ in 1970 , and increased to 2,330 $(30.3 \%)$ in 1994, which was the first time that women comprised more than $30 \%$ of all entrants. In 2007, the total number of persons entering medical school was 7,396, of whom 2,429 (32.7\%) were women (T. Hasegawa, personal communication). This growing number of female physicians is one of the central issues related to the shortage of hospital doctors in Japan. First, female physicians often stop work after having children in their $30 \mathrm{~s}$ when they are in the prime of life, and return to the workforce once they have finished raising their children. This work pattern is known as the "M-shaped curve", 1 and it is found in the general Japanese female workforce as well as among female physicians. Second, more women shift from hospitals to clinics sooner after graduating from medical school compared with men. According to the 2006 report from the Japanese Ministry of Labor and Welfare, more than $60 \%$ of female physicians move to clinics or stop working within 20 years of graduation, while half of the men are still working at hospitals. ${ }^{2}$

In addition, relatively few women become cardiologists, with female members of the Japanese Circulation Society (JCS) and female Board Certified Members of the Society only accounting for $11.6 \%$ and $7.4 \%$ of all members, respectively, in 2008, although women were reported to account for $17.2 \%$ of all physicians in $2006 .{ }^{3}$ This problem is not specific to Japan and the situation is more serious in other countries. In the USA, $44.8 \%$ of graduating medical and surgical trainees were women in 2007-2008, and the percentage of female residents in the field of internal medicine and female fellows in cardiology was $43.9 \%$ and $18.8 \%$, respectively. ${ }^{4}$ In the UK, women accounted for $60.9 \%$ of all students accepted by medical schools in 2002, but were only $16.8 \%$ of trainees and only $7.4 \%$ of consultants in the cardiology field. ${ }^{5}$ In Canada particularly, the number of cardiovascular specialists is declining and enough new specialists may not be able to be recruited, because young graduates (especially women) tend to consider the flexibility and predictability of work when choosing a specialty. ${ }^{6}$

Cardiovascular diseases often cause emergencies, so the practice of cardiology requires sufficient manpower and various facilities, including intensive care units in specialist hospitals. It is essential to have an appropriate

Received March 31, 2009; revised manuscript received July 7, 2009; accepted July 8, 2009; released online September 10, 2009

Department of Internal Medicine, Division of Cardiology, Nippon Medical School, Tokyo, Japan

Mailing address: Yayoi Tetsuou Tsukada, MD, Department of Internal Medicine, Division of Cardiology, Nippon Medical School, 1-1-5

Sendagi, Bunkyo-ku, Tokyo 113-8603, Japan. E-mail: yayotuka@nms.ac.jp

All rights are reserved to the Japanese Circulation Society. For permissions, please e-mail: cj@j-circ.or.jp 
Table. Back Ground of Survey Respondents

\begin{tabular}{|c|c|c|c|}
\hline & Subtotal & Men & Women \\
\hline \multicolumn{4}{|l|}{ Faculty\&Fellows (Group F, n=195) } \\
\hline Subtotal of responders ( $\%$ of group and each sex) & $83(43 \%)$ & $58(37 \%)$ & $25(63 \%)$ \\
\hline Duration of career (years) & $16.4 \pm 9.4$ & $18.1 \pm 8.9$ & $10.8 \pm 6.4$ \\
\hline \multicolumn{4}{|l|}{ Position $(\%)^{\dagger}$} \\
\hline Professor & $5(82 \%)$ & $5(82 \%)$ & NA \\
\hline Associate professor, Senior assistant professor & $9(82 \%)$ & $9(82 \%)$ & NA \\
\hline Assistant professor & $29(38 \%)$ & $24(35 \%)$ & $6(86 \%)$ \\
\hline Full-time fellow & $3(75 \%)$ & $3(75 \%)$ & $1(100 \%)$ \\
\hline Part-time fellow & $12(67 \%)$ & $1(3 \%)$ & $11(73 \%)$ \\
\hline Graduate student & $5(100 \%)$ & $3(100 \%)$ & $2(100 \%)$ \\
\hline Senior resident & $2(12 \%)$ & $0(0 \%)$ & $2(50 \%)$ \\
\hline Visiting lecturer & $8(62 \%)$ & $7(58 \%)$ & $1(100 \%)$ \\
\hline Affiliated hospital fellow & $1(3 \%)$ & $1(4 \%)$ & $0(0 \%)$ \\
\hline Studying abroad or at another national institution & $9(100 \%)$ & $5 / 5(100 \%)$ & $4(100 \%)$ \\
\hline Other & $0(0 \%)$ & NA & $0(0 \%)$ \\
\hline \multicolumn{4}{|l|}{ Alumni (Group A, n=155) } \\
\hline Subtotal of responders (\% of group and each sex) & $43(28 \%)$ & $35(27 \%)$ & $8(31 \%)$ \\
\hline Duration of career (years) & $24.7 \pm 8.8^{*}$ & $24.6 \pm 9.1 *$ & $24.9 \pm 7.9 *$ \\
\hline \multicolumn{4}{|l|}{ Clinical position $(\%)^{\dagger}$} \\
\hline Academic (clinical) & $3(33.3 \%)$ & $2(13 \%)$ & $1(100 \%)$ \\
\hline Academic (basic science) & $4(67 \%)$ & $4(67 \%)$ & NA \\
\hline General hospital & $8(20 \%)$ & $7(20 \%)$ & $1(20 \%)$ \\
\hline Clinic & $27(29 \%)$ & $28(37 \%)$ & $6(35 \%)$ \\
\hline Other or unknown & $2(28.3 \%)$ & $2(50 \%)$ & $0(0 \%)$ \\
\hline \multicolumn{4}{|l|}{ Total $(\mathrm{n}=350)$} \\
\hline Responders (\% of all responders and percentage of each sex) & $127(36 \%)$ & $93(33 \%)$ & $34(50 \%)$ \\
\hline
\end{tabular}

$\uparrow \%$ of responders with the indicated position, both overall and of each sex.

*P $<0.001$ vs Group A.

number of cardiologists in such specialist hospitals. If female physicians continue to leave work or do not choose cardiology as a specialty, a shortage of cardiologists will soon occur in Japan.

The cardiology societies of many countries are concerned about this shortage of cardiologists and are trying to attract talented young doctors through various activities, including the provision of role models and/or mentors for female residents and networks for women in cardiology. Cardiologists in Japan also need to assess the problems of female cardiologists and develop countermeasures or a shortage of cardiologists will soon occur here, as has happened in other countries. To identify solutions that would allow female cardiologists to continue to work, we surveyed faculty members, fellows, and alumni of the Department of Cardiology at Nippon Medical School to investigate gender differences of work and life, as well as impediments to retention of female cardiologists in the workforce.

\section{Methods}

\section{Study Population}

The target population consisted of 350 cardiologists (282 men, 68 women), including 195 faculty members/fellows (senior residents, graduate students, research fellows, and faculty members: group F) and 155 alumni who had worked in the cardiology field (group A). They were members of the Department of Medicine, Division of Cardiology, at Nippon Medical School (Tokyo, Japan). Alumni were enrolled if their estimated age was under 65 years, which is the general retirement age in Japan, so the cut-off year for their graduation was set at 1968 .

\section{Questionnaire Survey}

A 28-item questionnaire was designed to obtain personal data (marital status, children, house-hold responsibilities, and childcare responsibilities) and professional issues for cardiologists (practice setting, working hours, and job satisfaction). The responders were also asked to consider factors that might prevent women from continuing to work as hospital cardiologists and how solutions could be devised.

On August 10, 2007, the questionnaire was sent with a covering letter that explained the purpose of the survey. All questionnaires that were returned by the end of August were included in the analysis.

For detailed analysis, group A and group F were divided by gender, then group $\mathrm{F}$ subjects of each gender were divided by whether they had children or not. Because only 1 woman alumnus without children responded, we did not divide group A in this way.

\section{Statistical Analysis}

Data are presented as the mean \pm SD or as number (percentage). Categorical values were compared by the chi-square test and continuous variables were compared by the unpaired t-test, with a $\mathrm{P}$ value $<0.05$ being considered significant. Analyses were performed with GraphPad InStat package ver. 3.06 (GraphPad Software, Inc, San Diego, CA, USA).

\section{Results}

There were 127 responders (36\%) of the 350 persons who received questionnaires: 34 women $(50 \%)$ and 93 men (33\%) responded. The response rate of current faculty members/fellows (54\%) was higher than that of the alumni $(28 \%)$. The average career length in group $\mathrm{F}$ was 12.3 years for men and 9.8 years for women, and 24.6 years for men and 24.9 years for women in group A (Table). 
A

\begin{tabular}{|lcccccc}
\hline & \multicolumn{3}{c}{ Men } & \multicolumn{3}{c}{ Women } \\
\cline { 2 - 6 } & Group F & Group A & Total & Group F & Group A & Total \\
\hline \multirow{2}{*}{ Married (\%) } & 46 & 30 & 76 & 15 & 6 & 21 \\
& $(83.6 \%)$ & $(88.2 \%)$ & $(85.4 \%)$ & $(57.7 \%)$ & $(75.0 \%)$ & $(66.7 \%)$ \\
\hline \multirow{2}{*}{ With children $(\%)$} & 33 & 27 & 60 & 10 & 7 & 17 \\
& $(60.0 \%)$ & $(83.3 \%)$ & $(69.2 \%)$ & $(38.5 \%)$ & $(87.5 \%)$ & $(50.0 \%)$ \\
\hline
\end{tabular}

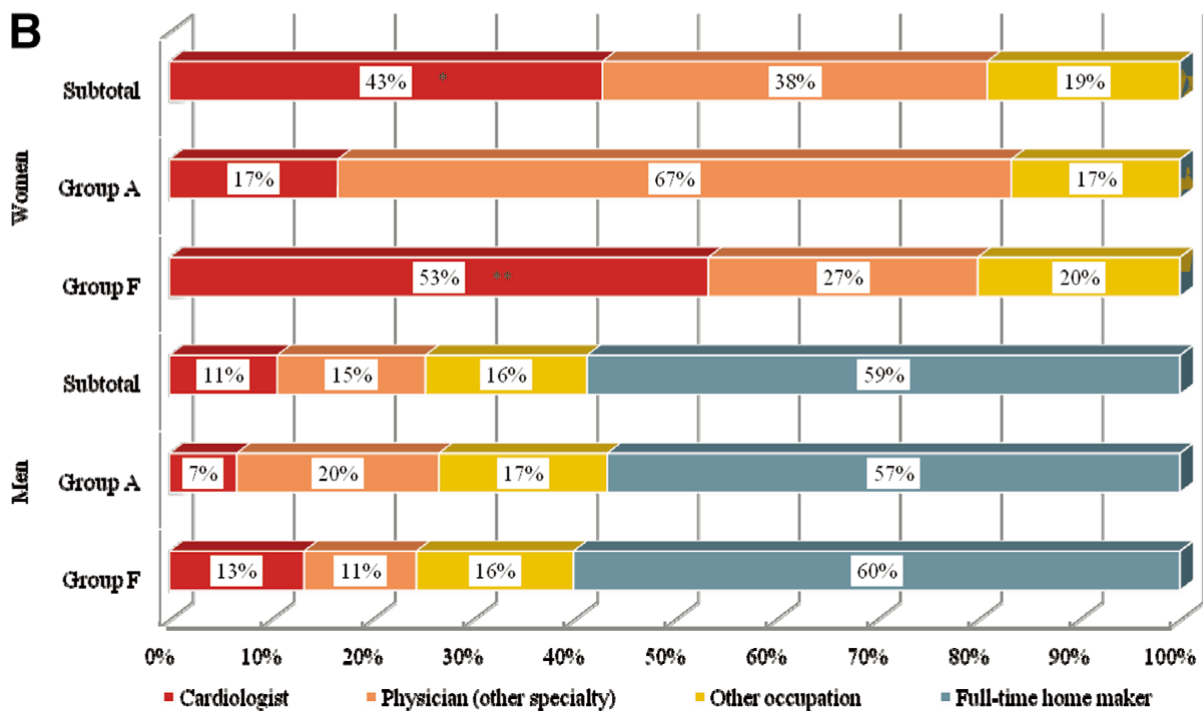

Figure 1. Personal and family matters. (A) Family status. $* \mathrm{P}<0.05$ vs all women. (B) Spouse's occupation. $* \mathrm{P}<0.05$ vs all men, $* * \mathrm{P}<0.005$ vs group $\mathrm{F}$ men.
A

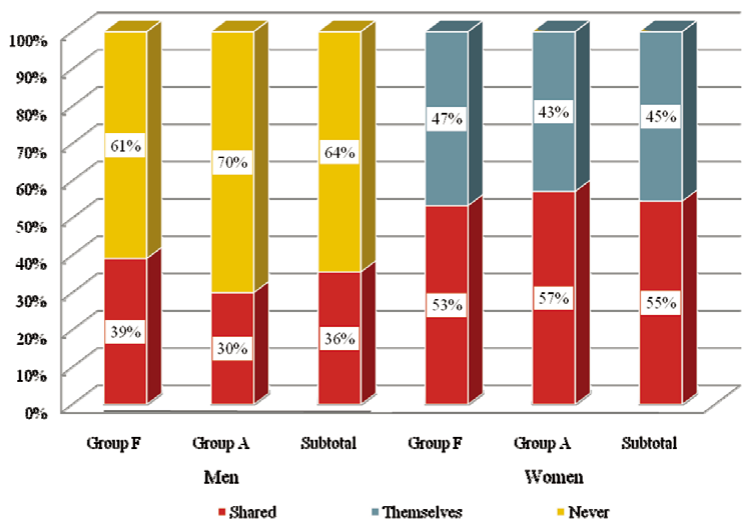

B

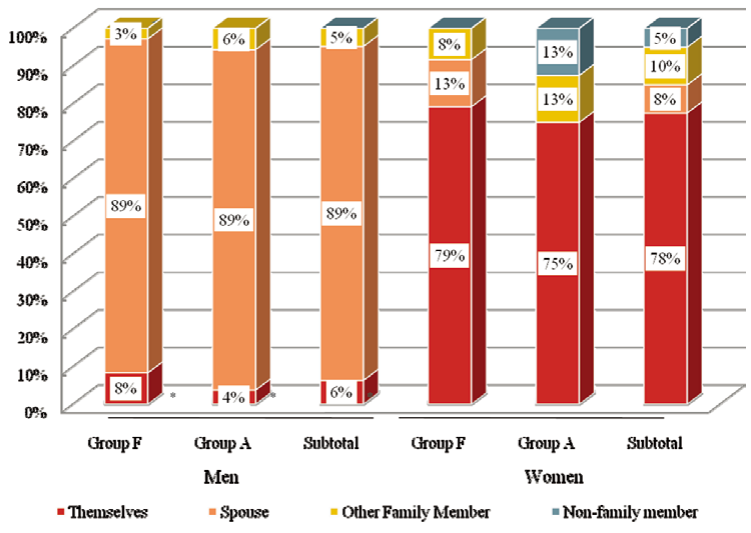

Figure 2. Household and family responsibilities. (A) Division of housework. (B) Family responsibilities. ${ }^{*} \mathrm{P}<0.0001$ vs men.

\section{Personal and Family Issues}

Women were less likely to be married than men $(85 \%$ of men were married vs $67 \%$ of women, $\mathrm{P}<0.05$ ). Among married cardiologists, women were less likely to have children than men, but the difference was not statistically significant (69\% of men vs $50 \%$ of women); $80 \%$ of the women were married to physicians, including $43 \%$ who were married to cardiologists and $38 \%$ married to physicians in other fields. In contrast, 59\% of the men were married to stay-at-home spouses. This difference was more prominent in group $\mathrm{F}$, with more than half of the women being married to cardiologists (53\%), whereas $60 \%$ of the men had stay-at-home spouses (Figure 1).

\section{Housework and Childcare}

Fewer men shared household duties with their spouses compared with women $(36 \%$ vs $55 \%, \mathrm{P}<0.001)$. In addition, $64 \%$ of men did do not any housework and $45 \%$ of women did it all themselves. There was also a striking gender difference with respect to childcare because $78 \%$ of female cardiologists stated that they were mainly responsible for childcare, whereas $89 \%$ of men responded that their spouses handled childcare $(\mathrm{P}<0.0001$ for men vs women $)$. More women felt that childcare hindered their ability to practice cardiology (39\% of men vs $79 \%$ of women, $\mathrm{P}<$ $0.0001)$. Among group F subjects without children, women were more concerned about future problems related to housework and childcare (43\% of men vs $80 \%$ of women, $\mathrm{P}<0.0001$ ) (Figure 2).

\section{Working Hours}

This survey revealed that approximately $42 \%$ of all cardiologists worked more than $60 \mathrm{~h}$ per week. Male cardiolo- 
A

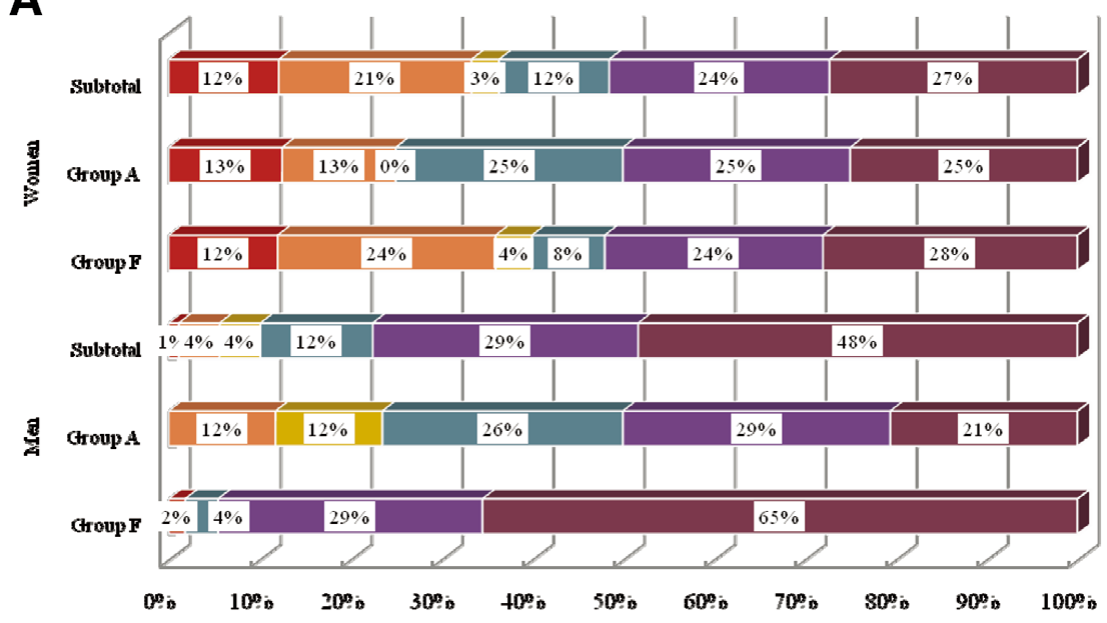

B

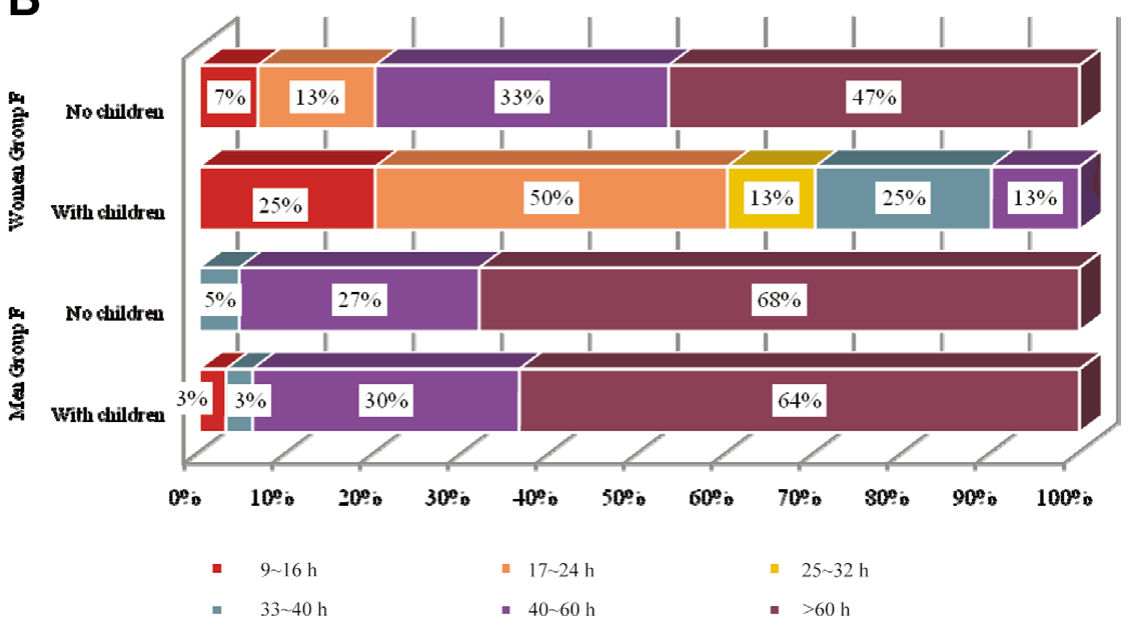

Figure 3. Working hours. (A) Comparison of Group F and Group A. (B) Comparison of members of Group F with or without children. gists tended to work longer hours than females, but $47 \%$ of women without children worked more than $60 \mathrm{~h}$ per week and this rate was the same as for male cardiologists. In particular, approximately two-thirds of the men and half of the women without children from group $\mathrm{F}$ worked more than $60 \mathrm{~h}$ (Figure 3).

\section{Career Satisfaction}

Female cardiologists were significantly more likely to be dissatisfied with their career than male cardiologists $(17 \%$ of men were dissatisfied vs $34 \%$ of women, $\mathrm{P}<0.005$ ). This gender difference in job satisfaction was most prominent among cardiologists from group $\mathrm{F}$ without children, because $38 \%$ of women from group $\mathrm{F}$ without children were moderately or very dissatisfied with their career vs only $14 \%$ of the men from this group without children $(\mathrm{P}<0.005)$. Women from group $\mathrm{F}$ without children reported as the reasons for dissatisfaction that they had little private time because of long working hours and that overwork made them exhausted. In contrast, women from group F with children reported that they would like to work longer hours without time limitations, but could not do so because of family responsibilities (Figure 4).

\section{Future Expectations for Female Cardiologists}

Men were less likely to expect that female cardiologists will continue to increase compared with women (80\% vs $97 \% \mathrm{P}<0.05)$. Men from group A were the least likely to expect an increase of female cardiologists in the future (64\% of men in group A vs $90 \%$ of men in group F, $100 \%$ of women group $\mathrm{A}$, and $90 \%$ of women in group $\mathrm{F}, \mathrm{P}<$ $0.005)$. There was no gender difference in the response to the question asking whether each person would recommend his/her daughter to become a cardiologist if he/she had a daughter (56\% vs 58\%). In group $\mathrm{F}$, however, a high proportion of women without children said that they would not recommend their daughter to become a cardiologist if they had a daughter (77\% of women without children vs $20 \%$ of women with children, $45 \%$ of men with children, and $45 \%$ of men without children, $\mathrm{P}<0.05)$.

\section{Obstacles to Job Continuity}

General Both men and women answered that childcare, pregnancy/childbirth, and education of children are common impediments to the retention of female physicians in the workforce. Women were more concerned about caring for the elderly (88\%) and about job transfer for themselves $(69 \%)$ than men. In particular, women without children answered that job transfer for themselves was one of the biggest obstacles, which suggested that women place more value on the current working environment. Also, significantly more women than men from group $\mathrm{F}$ considered that 


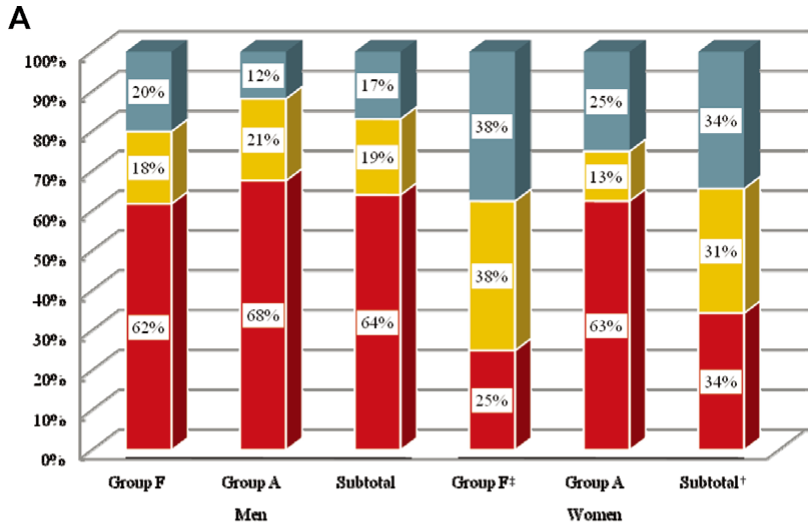

B

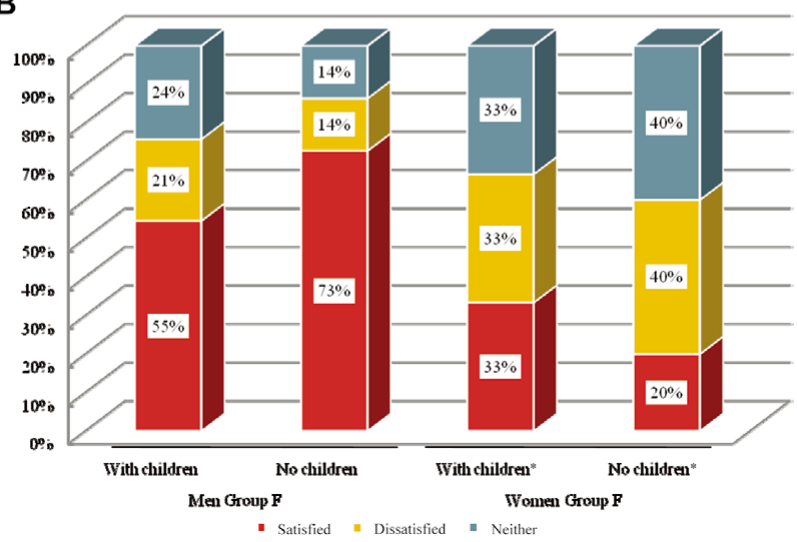

Figure 4. Career satisfaction. (A) Comparison of Group F and Group A. (B) Comparison of Group F members with or without children. ${ }^{\dagger} \mathrm{P}<0.005$ vs men, ${ }^{\star} \mathrm{P}<0.005$ men from group $\mathrm{F},{ }^{*} \mathrm{P}<0.05$ vs men without children. interpersonal relationships and sexual harassment at work were problematic $(46 \%$ vs $22 \%, \mathrm{P}<0.05)$ (Figure 5).

Specific With regard to specific obstacles for female cardiologists, men and women both reported that long working hours was the most problematic issue, but significantly more women reported this than men $(76 \%$ vs $94 \%$, $\mathrm{P}<0.05)$. In addition, woman were more concerned than men about radiation exposure $(88 \%$ vs $59 \%, \mathrm{P}<0.01)$. In particular, all of the women with children were concerned about radiation exposure (100\%) (Figure 6). Similarly women with children felt that it was more difficult to maintain their skills and to update their knowledge of cardiology $(66.7 \%)$ than men or women without children, although there were no significant differences between these groups.

\section{Increasing Retention of Female Cardiologists}

All female cardiologists wanted a variety of job positions, including short working hours, shift work and work-sharing, which would allow them more flexibility and predictability of working hours. They also wanted a retraining system and childcare facilities for on-call and/or overnight duty. Compared with the expectations of men about the needs of female cardiologists, significantly more women actually wanted a retraining system $(100 \%$ vs $76 \%, \mathrm{P}<0.001)$ and a team-care system for general cardiology in the hospital (91\% vs $59 \%, \mathrm{P}<0.005)$.

\section{Discussion}

In the present study, we used a questionnaire survey to examine gender differences in the work and home life of cardiologists and the problems faced by women in the field of cardiology. Female medical students are less likely to choose cardiology as their specialty, and women have long

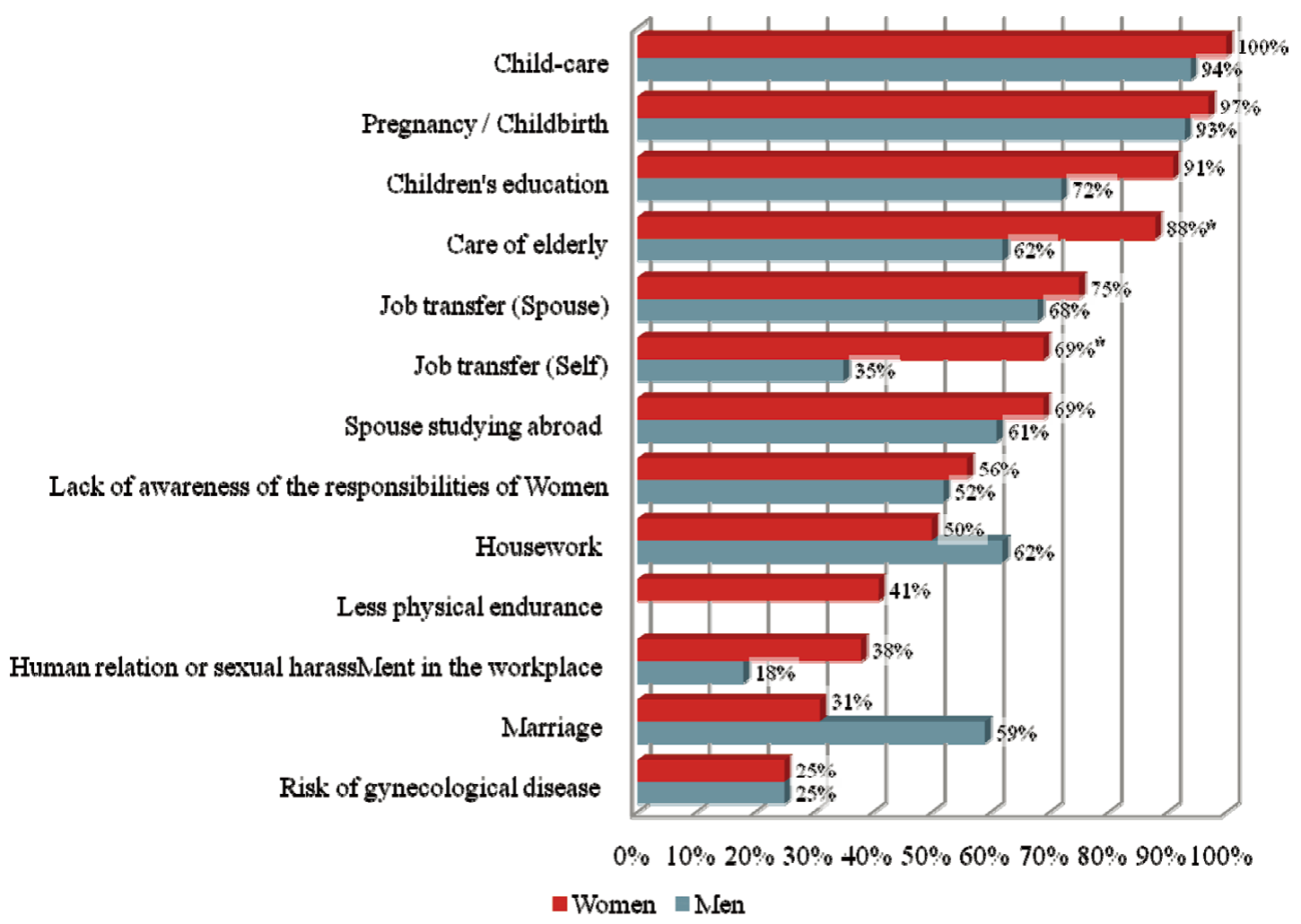

Figure 5. General career obstacles for female physicians. ${ }^{*} \mathrm{P}<0.05$ vs men. 


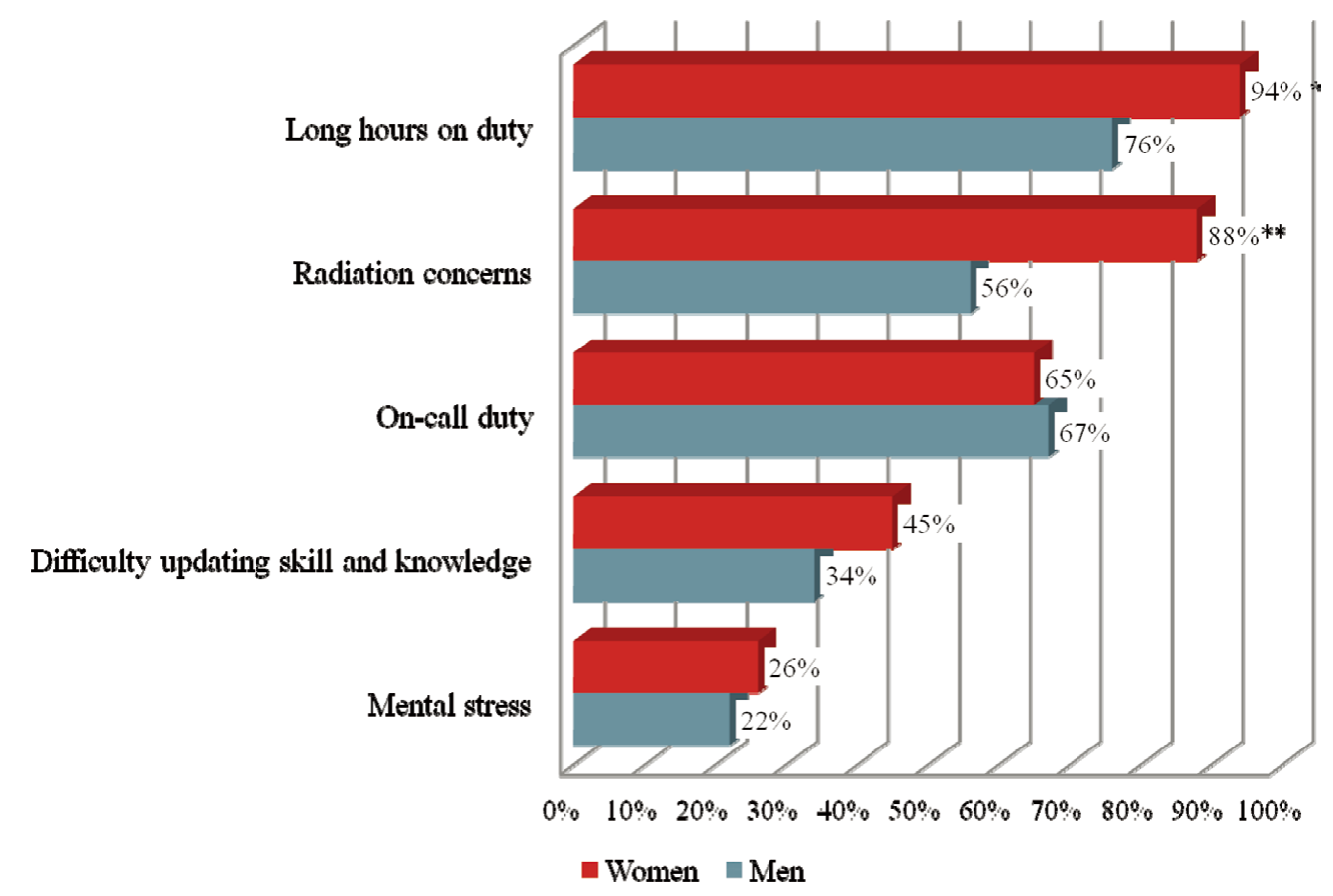

Figure 6. Career obstacles for female cardiologists. ${ }^{*} \mathrm{P}<0.05$ vs men, $* * \mathrm{P}<0.01$ vs men.

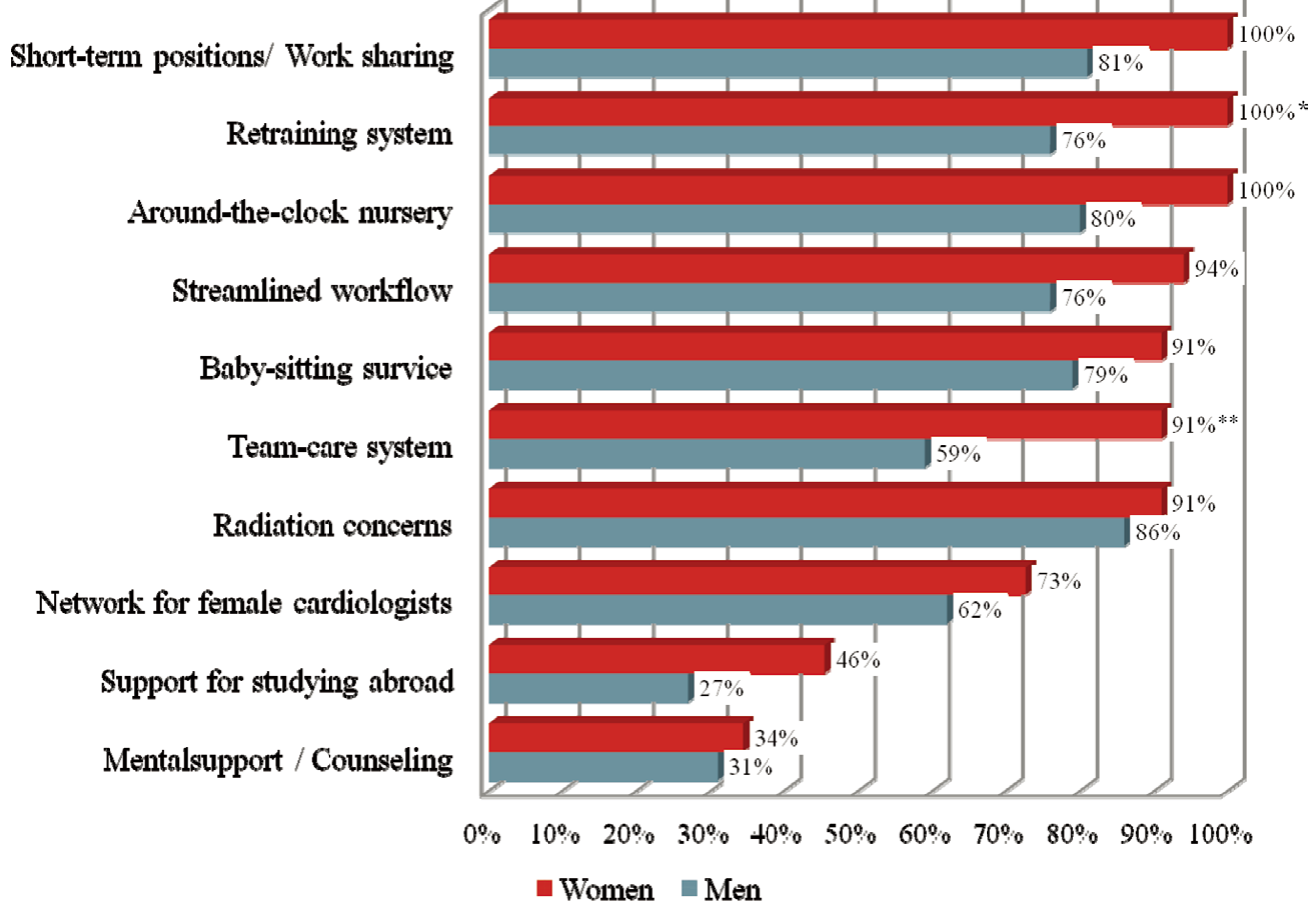

Figure 7. Solutions for retention of female cardiologists. $* \mathrm{P}<0.001$ vs men, ${ }^{*} * \mathrm{P}<0.005$ vs men.

been under-represented among cardiologists in Japan. It is an urgent issue to attract talented young doctors and keep them working in this field or we will face a shortage of cardiologists in the near future. We consider that better understanding between men and women is a key to solving this problem.

\section{Personal and Family Issues}

Female cardiologists were less likely to be married and/or to have children than male cardiologists. In addition, the majority of female cardiologists were married to other physicians, half of whom were also cardiologists. In contrast, $61 \%$ of male cardiologists were married to stay-at-home spouses and did not do any housework. As a result, the married female cardiologists considered that childcare and 
housework were twin burdens limiting their careers. The same situation exists in the USA, where $65 \%$ of married male cardiologists have stay-at-home spouses. ${ }^{7}$ According to the American College of Cardiology (ACC) survey, female cardiologists made the following arrangements for childcare: a paid live-in full-time caregiver (29\%), a paid full- or part-time caregiver in the home $(63 \%)$, or private or institutional out-of-home care $(45 \%)$. They also added childcare for night shifts/on-call duties (51\%), but only $16 \%$ of them used an unpaid relative. In contrast, Japanese female workers have few options for childcare. Most female doctors depend on unpaid relatives or unpaid relatives and out-of-home childcare $^{8}$ because employment costs for caregivers are extremely high in Japan compared with the USA, and because it is impossible to have a live-in caregiver in the smaller Japanese houses. If male cardiologists continue to work long hours as they do at present, female cardiologists married to other cardiologists have little choice except to do both their jobs and the housework. In fact, all cardiologists (not only female cardiologists) should be able to take time off easily in order to share family responsibilities.

\section{Obstacles to Job Continuity}

Male and female cardiologists equally considered that the general obstacles to the careers of female physicians were childcare, pregnancy/childbirth, and children's education, as has been found in other surveys. ${ }^{8,9}$ There was a gender difference with regard to "care of the elderly" and "job transfer", with more women considering these as obstacles. In Japan, the traditional caregivers for the elderly have been women (ie, wives, daughters-in-law, and daughters). Because of the recent increase in the childbearing age, some women have to take care of both their children and elderly relatives at same time, which is very challenging for a busy cardiologist. In general, support for female physicians in Japan is currently focused on support for childbearing because a high percentage of women are in their child-bearing years. However, we also have to recognize that female cardiologists are concerned about caring for the elderly, even among young women who do not yet have families. We need to establish a support system in the workplace for care of the elderly that assists physicians to continue working.

Furthermore, women were significantly more concerned about occupational radiation exposure than men. In recent years, interventional cardiology has advanced considerably so that radiation exposure has become more frequent. For female cardiologists who are planning pregnancy, occupational radiation exposure cannot be ignored. In 2006, the JCS published a "Guideline for Radiation Safety in Interventional Cardiology", ${ }^{10}$ written in a question-andanswer format, making it easy to understand even for young residents without expertise in cardiovascular medicine. However, this guideline is not yet fully recognized by people working in the clinical cardiology field. In order to avoid unnecessary concern about radiation, information about occupational radiation safety needs to be included in the continuing education of cardiologists. In addition, the guideline recommends that the administrator of each interventional radiology division should prepare rules for notification of pregnancy to assist female cardiologists and establish a maternal-friendly workplace. Institutions should decide the rules about notification of pregnancy for all female medical staff engaged in interventional radiology.

According to this survey, women were more interested than men in a retraining system and team care for general cardiology. In fact, $66 \%$ of female cardiologists with children felt that it was difficult to update their knowledge of cardiology and maintain their skills, and all female cardiologists wanted a retraining system. It is crucial to provide part-time training for young residents who have not completed their initial training. Considering the recent increase in medical litigation, it is natural that female cardiologists who have been away from work for some time should be concerned about returning to the workforce. Actually, it should not be problematic to return to work after time off because of family responsibilities if they have completed their training. Even so, women in an isolated situation have psychological barriers to rejoining the workforce. To overcome such barriers and boost self-confidence, retraining would be useful. Accordingly, retraining should be provided for all cardiologists who want it and should be readily accessible. The JCS is expected to establish a training system at certified institutions.

\section{Low Job Satisfaction of Female Cardiologists}

A noteworthy point revealed by this survey is that women were significantly less satisfied with their work than men. Women without children complained of physical and mental exhaustion caused by excessively long working hours, while women with children stated that limitation of their career because of family responsibilities was the main reason for dissatisfaction. Improving the working environment and developing more attractive jobs for women may be necessary to solve this problem. Furthermore, it is a sad fact that young female cardiologists without children stated that they would not recommended their daughter to become a cardiologist if they had a daughter. In 1998, the ACC also reported that female cardiologists were less satisfied than male cardiologists in the USA. ${ }^{11}$ Since then, the ACC and the American Heart Association have established a working group for women in cardiology and have tried to find ways to improve the work environment. As a result, both women and men have reported being more satisfied with work and the satisfaction rate was over $90 \%$ for both sexes in $2008 .{ }^{7}$ We need to determine the reasons for low job satisfaction among female cardiologists in Japan and achieve a similar improvement.

\section{Study Limitations}

This survey only included faculty members, fellows, graduate students, and alumni of the Division of Cardiovascular Medicine at a private medical school in Tokyo. Thus, the results might have been different if the survey had assessed other specialties (eg, physicians, pediatricians, or surgeons), other locations (country areas rather than Tokyo), and institutional background (public rather than private). These conditions may be important factors affecting job and lifestyle. However, the results were not so different from those of previous surveys of cardiologists performed in other countries, so there may not be big differences among cardiologists elsewhere in Japan. Hence, if we want to take measures to support female cardiologists, it is necessary to consider the factors identified by this survey.

Moreover, we did not investigate sexual discrimination, salaries, and promotion, because most of the responders were working at the same institution. Sexual discrimination affects female cardiologists in other countries, 5,7 and we need to obtain more objective data about such discrimination by performing a completely blinded study in Japan. An 
expert committee should be established by the JCS to obtain further information about possible solutions for retaining female cardiologists.

\section{Conclusions}

The number of men and women entering medical school should be approximately equal, reflecting their numbers in society. An increase of female physicians is a current trend all over the world. There must be no delay in taking action to recruit young talented doctors by improving their working conditions. The following measures should be taken: (1) provide family-friendly working conditions in hospitals; (2) offer various positions that can provide flexibility and predictability for women, such as short working hours, shift work and work-sharing; (3) establish a retraining system; and (4) develop work and research opportunities that are attractive to women. The policy regarding work-life balance should aim to allow all cardiologists, not just male cardiologists, to work continuously. The JCS will need to play a central role, as have cardiology societies in other countries. It is necessary to raise general awareness of work-life balance issues among male cardiologists, especially those who serve as faculties or chiefs of cardiovascular departments. This survey may provide important information for understanding the problems of female cardiologists. Both male and female cardiologists need to seek a new way forward, based on mutual understanding and respect.

\section{Acknowledgments}

We thank the members of the Department of Cardiology at Nippon Medical School for providing detailed personal information for our survey. We also thank Dr Toshihiko Hasegawa for providing statistical data about doctors and students in Japanese medical schools.

\section{References}

1. Nakano E. The participation of married women in the labor force in relation to their level of education: With a focus on their marriage and childbearing periods. Jinko Mondai Kenkyu [J Popul Probl] 1984; 36-52 (in Japanese)

2. Ministry of Health Labour and Welfare. The Report from Study Group on the Supply and Demand of Physicians (in Japanese). Last update 2006.8.9. Available from http://www.mhlw.go.jp/shingi/2006/ 07/dL/s0728-9c.pdf

3. Ministry of Health Labour and Welfare. Statistics Information Department. Survey of physicians, dentists, and pharmacists: 2006. Tokyo: Kosei Tokei; 2008 (in Japanese).

4. Brotherton SE, Etzel SI. Graduate medical education, 2007-2008. JAMA 2008; 300: $1228-1243$.

5. Timmis AD, Baker C, Banerjee S, Calver AL, Dornhorst A, English $\mathrm{KM}$, et al. Women in UK cardiology: Report of a Working Group of the British Cardiac Society. Heart 2005; 91: 283-289.

6. Graham MM, Kells CM. The girls in the boys' club: Reflections from Canadian women in cardiology. Can J Cardiol 2005; 21: 1163-1164.

7. Poppas A, Cummings J, Dorbala S, Douglas PS, Foster E, Limacher MC. Survey results: A decade of change in professional life in cardiology: A 2008 report of the ACC women in cardiology council. $J$ Am Coll Cardiol 2008; 52: 2215-2226.

8. Tsubakio Y, Ida K, Iwamura C, Oka H, Kuniyoshi Y, Nakanishi A, et al. The current status of female hospital doctor. J Osaka Med Assoc 2007; 40: $25-28$.

9. Amano K. The working environment of female doctor in the cardiology field: Report of Health and Labour Sciences Research (ChildFamily Integrated Research Business). Tokyo, 2002.

10. Nagai R, Awai K, Iesaka Y, Ishiwata S, Kikuchi T, Sakurada S, et al. Guidelines for radiation safety in interventional cardiology (JCS 2006). Circ J 2006; 70(Suppl IV): 1247-1327.

11. Limacher MC, Zaher CA, Walsh MN, Wolf WJ, Douglas PS, Schwartz JB, et al. The ACC professional life survey: Career decisions of women and men in cardiology. A report of the Committee on Women in Cardiology. American College of Cardiology. J Am Coll Cardiol 1998; 32: 827-835. 